\title{
Community Engagement for Malaria Elimination in the Greater Mekong Subregion: a Qualitative Study Among Malaria Researchers and Policymakers
}

Nils Kaehler ( $\nabla$ dr.nils.kaehler@googlemail.com )

Mahidol Oxford Tropical Medicine Research Unit https://orcid.org/0000-0002-0555-0242

Bipin Adhikari

Mahidol Oxford Tropical Medicine Research Unit

Phaik Yeong Cheah

Mahidol Oxford Tropical Medicine Research Unit

Lorenz von Seidlein

Mahidol Oxford Tropical Medicine Research Unit

Nicholas PJ Day

Mahidol Oxford Tropical Medicine Research Unit

Arjen M Dondorp

Mahidol Oxford Tropical Medicine Research Unit

Christopher Pell

Amsterdam Institute for Global Health and Development

Research

Keywords: policymakers, community engagement, malaria, research, intervention, participation, population coverage

Posted Date: November 9th, 2021

DOI: https://doi.org/10.21203/rs.3.rs-1008558/v1

License: (c) (i) This work is licensed under a Creative Commons Attribution 4.0 International License.

Read Full License 


\section{Abstract}

\section{Introduction}

Community engagement has increasingly received attention in malaria research and program interventions, particularly as countries approach closer to malaria elimination. Although strategies and aspects of community engagement are constantly developing, little is known about how those who implement research or programs view community engagement. This article explores the perspectives of researchers and policy makers in the Greater Mekong Subregion (GMS) on community engagement for malaria control and elimination.

\section{Methods}

Semi-structured interviews were conducted among 17 policymakers and 15 senior researchers working in the field of malaria. All interviews were audio-recorded and transcribed in English. Transcribed data were analyzed using deductive and inductive approach in QSR NVivo. Themes and sub-themes were generated.

\section{Results}

Researchers and policymakers emphasized the importance of community engagement in promoting participation in malaria research and interventions. Building trust with the community was seen as crucial. Respondents emphasized involving authority/leadership structures and highlighted the need for intense and participatory engagement. Geographic remoteness, social, cultural, and linguistic diversity were identified as barriers to meaningful engagement. Local staff were described as an essential 'connect' between researchers or policy makers and prospective participants. Sharing information with community members, using various strategies such as visualization of message including creative and participatory methods were highlighted.

\section{Conclusions}

As malaria continues to decline across the GMS, countries have set elimination goals. In this context, policy makers and researchers involved in malaria prevention and control in the region viewed community engagement as crucial for promoting participation in research or programmatic interventions. Given the difficulties of the "last mile" to elimination, sustained investment in community engagement is needed in isolated areas of the GMS where malaria transmission continues.

\section{Introduction}

Over recent years, community engagement has received increasing attention in health research and program interventions [1]. What constitutes community and engagement is however debated, particularly because of the differences in its overall aims [2]. The breadth of community engagement is encapsulated 
by one widely used definition: a process of collaborative work with group of people affiliated by geographic proximity, interest or health issues, to address social and health challenges [3].

As malaria declines in areas, such as the Greater Mekong Sub-Region, countries are setting elimination as a goal. Concerted efforts are however necessary to achieve these goals [4]. Paradoxically, with diminished disease burden, funding and enthusiasm for case surveillance and treatment shrinks, while more resources are needed to track down the remaining cases $[5,6]$. Community engagement is increasingly recognized as the critical element in malaria elimination [5-7], for example, to ensure that last cases are identified and treated before they lead to focal outbreaks [7]. Recent studies on mass antimalarial administration in Asia and Africa have shown how appropriate community engagement can promote uptake of interventions aimed at achieving elimination $[4,8]$.

Scholarship around strategies for community engagement related to malaria interventions has recently burgeoned $[1,2,4,7,9-15]$. This has taken place in the context of discussions about moving from a more top-down to bottom-up approach $[9,16,17]$. In top-down approaches, prioritizing, planning, and implementing a health program occurs without the active involvement of the communities, whereas a more bottom-up approach combines agendas proposed by the community with the participation and engagement of community structures $[4,9]$. Even with a participatory approach, meaningful engagement often remains elusive because of pre-existing power dynamics [18].

Community engagement tools or activities are also developing to reflect these changes. For instance, community meetings are less likely to comprise top down instructions and more likely reflect an open dialogue [2]. In addition to providing feedback into the study design, meaningful participation entails coexecuting the study $[19,20]$. Involving community members rather than outsiders has the potential to adapt study plans and interventions to local values, culture, and tradition [14, 21].

Engagement also depends on the 'human infrastructure' of community members and researchers or implementers [22] in which social relationships are critical that can engender trust $[1,15,19]$. Trust is commonly identified as a key element of successful community engagement [21]. However, to maintain a level of trust, researchers/implementers and the community members need to continuously invest in building relationship through for example, dialogue, and participation to ensure the issues and problems from all stakeholders are addressed $[1,19]$. Building trust through community engagement is likely to be a key to ensure the effectiveness of malaria elimination programme.

Field research has examined the aims and approaches of community engagement, but less is known how it is perceived, and prioritized by policymakers, researchers, and stakeholders who are central to malaria elimination policy and implementation. This article explores researchers and policy makers' perspectives on the role and strategies of community engagement for successful elimination of malaria relevant for GMS nations.

\section{Materials And Methods}


Details of the methods utilized in the current study have been described previously [5, 23]. Briefly, interviews were conducted between October 2016 and April 2017 among a total of 32 participants

All respondents were recruited based on their expertise or decision-making roles in malaria control, prevention and elimination programs in the GMS, such as policymakers from Cambodia, Thailand, Vietnam Myanmar and Laos. Stakeholders who had influence in policies also represented World Health Organization (WHO) and international funding agencies such as the Clinton- or the Bill and Melinda Gates Foundation. Respondents were identified through a combination of 1) bibliography and web searches; 2) snowball approaches using authors' professional networks. The appropriateness of a potential respondents in terms of offering information to address our research question was assessed based on their web-searches for malaria related works, and contributions, and were regularly discussed among the core members of the research-team.

Based on the prepared list of potential respondents, contact details were subsequently collated and potential respondents were mostly contacted by email. Among the list of potential respondents prepared by the research team, none explicitly refused to participate but two were not responsive and could not be interviewed. Recruitment was continued until theoretical saturation (where newly collected information did not provide additional insights) [24,25]. To achieve a maximum diversity of opinions subjects endorsing different approaches to malaria elimination in the GMS were approached.

A topic guide for the semi-structured interviews was developed, based on the initial research questions. Topics included MDA, Malaria Elimination and Community Engagement. An iterative and flexible approach was taken to question to elicit in-depth information, as well as to ensure that relevant topics were not neglected.

All interviews were conducted between October 2016 and April 2017 at different locations in Myanmar, Thailand, Laos, Cambodia, Vietnam and USA. Whenever possible the interviews were conducted "face-toface" on study site of a pilot malaria elimination strategy project, at selected international tropicalmedicine conferences, or at ministerial- or governmental offices. If a "face-to-face" interview was not possible, alternatives procedures via Skype or telephone were selected. Two respondents responded to an email due to exceptional circumstances.

All interviewers were conducted by the first author who is a medical doctor with a master's degree in public health and tropical medicine, as well as training in qualitative- and quantitative social-science research methods. Data collection and analysis was supervised by an experienced qualitative social scientist (the last author). All interviews ranged from 20 to 90 minutes in length and were conducted in English. Interviews with policy makers- and funders were longer than with malaria scientists. All Interviews were audio-recorded and subsequently transcribed verbatim by an independent transcriber. The interviewer checked all transcripts for accuracy.

All Interview-transcripts were analysed using a qualitative data-analysis software (NVivo 11; QRS International, USA). A codebook which was adapted from previous qualitative research on community 
engagement and TME (in Cambodia, Laos and Myanmar) was used [8]. Line-by-line coding of transcripts used pre-established themes (deductive approach), followed by themes which emerged during further data-analysis (inductive approach). Further analysis was performed by identifying and explaining "prominent themes- and patterns" amongst respondents and outliers. coding was initially performed independently by two researchers (NK and BA). Disagreements among the researchers were resolved by discussion and only agreed on codes were finally presented.

Initial data collection was conducted as part of the Targeted Malaria Elimination (TME) research project $[8,26]$. TME was a cross-over community randomized controlled trial conducted in Thai-Myanmar border, Myanmar, Cambodia, Laos and Vietnam which entailed mass antimalarial administration and quarterly parasitemia surveys for a year [26]. The ethical approvals were obtained from all countries where TMErelated research was conducted: Laos: Lao National Ethics Committee for Health Research (Ref. No. 0132015/NECHR), Government of the Lao PDR and the Oxford Tropical Research Ethics Committee (101513); Cambodia: National Ethics Committee for Health Research Cambodia (NECHR 0042\& 0051) and the Oxford Tropical Research Ethics Committee (OXTREC; 1017-13); Vietnam: the Institute of Malariology, Parasitology and Entomology in Ho Chi Minh City (185/HDDD), the Institute of Malariology, Parasitology and Entomology in Qui Nhon and the Oxford Tropical Research Ethics Committee (1015-13); Myanmar: ethics Review Committee of the Department of Medical Research (Ref: 74/Ethics 2014) and the Oxford Tropical Research Ethics Committee (23-15; 1015-13), the Tak Province Community Ethics Advisory Board and the village committees. Further ethical approval was obtained from "Oxford Tropical Research Ethics Committee" (OxTREC), and was approved on 31 January 2017 (Unique Protocol ID: OxTREC ref: 5122-16). Verbal informed- consent was obtained from all respondents prior to the interviews. All respondents were given an explanation about the study, the voluntary nature of their participation and its rationale. The respondents were briefed that they can drop out of the study - at any time - during the interviews, without providing any justification. Confidentiality and anonymity were secured for all respondents.

\section{Results}

A total of 32 respondents participated in the study that included 17 policy makers and 15 leading malariologists. Policy makers included three females and 14 males; researchers included three females and 12 males. The balance of policymakers and researchers allowed us a fair comparison between their perspectives and to generate conclusions.

The findings are presented by themes that emerged during the interviews, integrating direct responses from both researchers and policy makers. The initial themes and sub-themes were further consolidated aligning with the research question and the final themes and sub-themes included

1. Aims of community engagement;

2. Strategies for community engagement;

3. Activities or tools for community engagement; and 
4. Challenges for effective community engagement.

\section{Aims}

Both policy makers and researchers described community engagement as an important aspect of research/programs to ensure prospective community members understand the study or programs, their objectives, benefits, possible complications and agreement to participate. Both researchers and policymakers said the main objectives of community engagement was to promote participation in research or programmatic intervention, and in the case of MDA, population coverage (figure 1).

One of the policymakers reflected on the modelling studies related to mass antimalarial administration, where high population coverage was emphasized to be critical for the success of this intervention.

So, the modelers have agreed that achieving high coverage is what you need to make MDA effective. If that's what you need to achieve, then of course that's where your community engagement comes in, because if you don't have a community that is convinced that this is a good idea you don't achieve coverage, then this thing will not be effective (SSI-P14)

Others reflected generically about why and how community engagement should be an integral part of the research or intervention.

... I think community engagement is a key thing. The community beforehand should be convinced, should be informed about the remedy and its benefit and so on and so forth ... (SSI-P8)

At the time of the interviews, several MDA trials were ongoing in Southeast Asia, and potential respondents were presented with a precis of these trials as part of the information sheet. Researchers generally expressed the outcome of community engagement in terms of MDA studies, particularly the critical role of high participation/population coverage in the success of MDA.

$C E$ is the essential method, it is very important tool, and it is the first activity to be implemented in the ME project before we can do a[n] MDA and MDA related activities (SSI-P24)

\section{Trust}

Both policy makers and researchers highlighted the goal and purpose of community engagement to build trust among the community members, which could ultimately affect participation. Nevertheless, several challenges were mentioned by both policy makers and researchers that may have an impact on this goal. With regard to selecting an appropriate person for community engagement in the community, someone who is respected, and popular in community was deemed to garner more trust than researchers who is an outsider to the community. 
They know the governor, they know the district governor, they know the community chief. Not us who make the trust; we use these people to make the trust. (SSI-P13)

Reflecting on the MDA studies, a few policymakers mentioned that when community members experienced adverse events due to antimalarials offered, the relationships and the trust towards the researchers (and their representatives) played a critical role in maintaining the acceptance of the MDA.

They understand well that they have to take this drug, even if there is some side effect or something like that (SSI-P4)

A few policymakers also clearly stated that early, and well-planned engagement strategies is critical, in contrast to engagement that reacts to setbacks in the community. Such setbacks and failures, often due to poor engagement strategies can generate a negative reputation/impression that can erode trust for future community engagement efforts and research.

I think the risk of failure is that once you use this tool, and it fails, it would be very hard to go back to that community and ask them to do it again. ... If you're going to do it, you better know that you're going to succeed." Because then you lose it forever (SSI-P7)

When it came to politics around research implementation, researchers clearly expressed the potential challenges in politically divided communities, where even slight inclination towards one group can mean other group can be against the whole research and explained that it could ruin the trust.

If you are perceived to be sided for one group or another, or sided with the government or against, then you are dead. You have to gain the trust of everybody and that's what we have been doing in community engagement. In fact, community engagement is only about trust. Trust at the highest level - your level one, your level two, your level three and all the way to the..... I would say in this case, the level five, which is the people is much more important; at the village level (SSI-P27)

Researchers also reported the importance of historical legacies of research, community members' past experience with the institution and researchers. Community members may suspect the true objectives of the study intervention because of bad experiences with former projects - this may also lead to difficulties in trust building and thus may threaten the whole study.

And we worked in a village 10 years ago ..., and we had been taking blood, and there was lots of discussion where we agreed that we could do that. And then we asked to take stools as well. And the village committee met and discussed our request to have stool samples. And we were sitting in the school on the little chairs, right? And the committee came in, a file of elderly men, and they looked terribly severe and unhappy. And the village head said, "We've considered." XXXX translated. It was in 'Lao theung'. It was in Lao. The village head said, "We've considered your request, and we agree." And they all laughed and banged their hands on the table and said, "Because we were very worried that you might sell our blood, but we're pretty damn sure you're not going to sell our stool. (SSI-P30) 
One researcher pointed out that to gain trust, it is crucial that the study team takes responsibility for all potential complication related to the study that may occur. According to the researcher many participants are not just worried about their own health but also of the potential consequences, complications related to the study that may bring to their families if they cannot work and support their family anymore.

\section{Strategies}

Most policy makers agreed on that the initial approach should go through the leadership of the community,

You engage first with the leaders and then once they have understood the story on why you are there and what is going to happen and go and inform the rest of the population..." (SSI-P1)

Many policy makers also stressed the importance of a formal approach, for example with documentation of official approval. One of the policy makers favored starting community engagement with a small group within the community who then can function as a bridge to other community members who may be more difficult to get access to and to convince to participate. Several policy makers pointed out that understanding the structure of the community's leadership, if possible, through local partners, makes it a lot easier to find out on who to contact first,

...find out specifically, every locale who we need to talk to, who the decision makers are. You know, maybe if you want to talk to the village chief but he has actually had a 50-year multi generation I feud with some other family over here. We always go through local partners who we hope to have that answer or have that kind of local information (SSI-P23)

Most researchers agreed with policy makers' opinion to initiate a community approach through the village leaders and for them to have a public meeting and discuss with the community (SSI-P30). Those village leaders may have different positions within in the community and, as mentioned above, should be selected if possible with the help of local partners.

First contact was usually made by village leaders, spiritual leaders, the health workers discuss with them and then they kind of organize further steps.. (SSI-P25)

\section{Activities}

In response to what could be various approaches and activities for community engagement, both policymakers and researchers shared a variety of activities that were and could be potentially appealing to community members. Most of the respondents described that utilizing audio-visual methods to communicate with community members to be important. 
Among those mentioned by policy makers were focus groups "... bringing everyone together, bringing up the leader and the one with influence....as well as other activities as drama, concerts, dances and showing movies. If you have DVDs, the TV is super" (SSI-P1)

Respondents described other tools such as the use of mass media, leaflet, hand-outs and visual representations. All these tools were thought to be more comprehensible for community members with poor literacy as well as being attractive and entertaining. Policymakers emphasized the need to utilize the latest technologies to reach community members.

Mass media campaigns through radio channels, with the very famous local program to ensure that people are aware of what is going to happen. We do almost a month of this before we start to do the MDA. (SSI-P16)

Most researchers stressed the need to visualize messages - including the study/program objective rather than just brief them to community members.

... we showed to each other village; we showed what was happening in the other villages. We had maps and we had graphs and things that are easy to visualize. Said you see in that other village over there; we did the same program and look at the number of cases. Last month they had no case of malaria. But your village, it's going up and up. Then people start to realize (SSI-P27)

Regardless of advancement in technologies, meetings were also described as crucial, conventional and comprehensive platform to get researchers' message get across.

"The most effective, right? I think, from what I observed - the meeting, the meeting with the villagers" (SSI P13)

A researcher also reflected on the MDA study in Laos, and emphasized the value of meetings where visually appealing posters were an important tool to discuss about the study.

The village where we worked with ethnic minority, we explained using posters, [which] people understand best (SSI-P29)

Several of these tools were mentioned by researchers and policymakers and they also emphasized entertaining activities, such as community games, were essential to boost familiarity and build relationships in the community.

\section{Challenges}

Researchers and policymakers highlighted several challenges for effective community engagement. One policy maker highlighted being naïve, with regard to understanding the community, as a wide-spread problem that has caused problems in several interventions in the past. 
This broad assumption that you can just walk up and go to people's place and assume that A) they're there, as if the whole of the community sits in a hut waiting for public health people to walk up, and B) you will just take whatever the people tell you to take is a mind-blowing assumption in my opinion. I don't know where that comes from (SSI-P14)

One challenge was that researchers pointed out the lack of universally applicable principles or strategies for community engagement. Researchers also mentioned the fact that (human and financial) resources were often insufficient for thorough community engagement. The high costs and effort was described a main reason why several governmental institutions are often hesitant in regard to implementing largescale community engagement.

Respondents also identified challenges related to ethnic, linguistic and cultural diversity, which can require resources when conducting engagement. Selecting a suitable and applicable approach to such a heterogenous group of community members was reported to be a major challenge and referred to Laos where there are scores of ethnic groups. Other challenges raised by respondents were due to remoteness and poor accessibility to the villages where malaria is endemic.

\section{Incentives}

The use of incentives was described as a very delicate topic in community engagement. Only a few researchers made the distinction between various forms of payment - reimbursement, compensation and incentives - made to research participants. The term 'incentives' was seemingly used by respondents to mean any form of material benefits offered to research participants.

The definition of what is an incentive and weather giving incentives is acceptable differed within and between both groups. Most policy makers opposed incentives in terms of cash payments due to ethical concerns. Some offered examples of how incentives (including the amount) is interpreted based on the local context. In most instances, community members can interpret incentives as payment or and exchange for the participation.

I think that is unethical. You cannot pay people to take drugs. This, I think, is forbidden by ethical committees (SSI-P5)

Nonetheless, policymakers did agree that participants needed to be compensated for their loss of opportunity and incurred costs attached to the participation in the research.

That they come and listen to you, or attend your MDA, whatever. What do they lose by not going to the rice field? These things need some compensation. (SSI-P6).

Researchers justified payments if deemed to be a compensation for lost opportunity or income for their participation in research but not as material benefits (incentives) to promote participation.

A few respondents, mostly policymakers raised an important issue of sustainability of offering incentives when it came to rolling out of large scale interventions or programmes. 
In contrast, most researchers considered compensation as necessary and crucial tool in recruitment. they saw payments as an integral component of standard research recruitment where potential participants need to be compensated for lost opportunity and income.

Lost income for an intervention which is, at this stage, experimental. You should pay for it." (SSI P32)

Other researchers stressed an importance of offering a community incentive rather than individual incentives. This was particularly relevant for very large-scale studies or programs, for which individual incentives would be a burden in terms of resources and time it requires.

Few researchers also pointed out the vulnerability of participants, especially in poor communities, where incentives may be important to ensure community members participate. Researchers also explained the lack of essential health care in remote communities, implying offering health care was thought to be important.

At least a few more services at that health post, not just malaria, but you have a little bit of paracetamol, penicillin, whatever.. (SSI-P26).

\section{Human Resources}

Human resources were deemed central in community engagement by both researchers and policymakers. Several policymakers reported challenges in regard to finding culturally competent staff with proper "education, writing and reading abilities, languages." (SSI-P6)

A few policy makers described the option of involving other prominent figures within the community, as for example local healers, who may be willing to cooperate and give access to other community members,

... with the benefit of this very deep, local, ethical, logical knowledge that is very locale specific we were able to convince to refer kids with that specific diagnosis to the hospital for the research team supplementing the local doctors to treat with proper anti-malarial (SSI-P23)

Several senior researchers stressed the importance of working with local staff to build the knowledge base and to implement the research/project efficiently

On the knowledge of the people who are doing the work, which are most of the people in this unit, ... people from the local population. 90\% of the people who do the work are Karen or Burmese or Thai. If you listen to them, they tell you a lot of things. They tell you that in this place, no, you can't go. We cannot. They know who to talk to be able to approach person $X, Y$ and Z. ((SSI-P27)

One of the researchers emphasized that specifically in the beginning of the intervention it is crucial to have local- and well-respected people on the team. 
Who know how to build a team which is going to be accepted, recognized and trusted by whatever community (SSI-P27)

Even the local recruitment was recommended to be handed over to the locally respected person. In support to finding staff that is locally respected 'We usually hired village leaders or some of his people [familiar person] to find people ... " (SSI-P25)

\section{Discussion}

As malaria continues to decline across the GMS and in several other regions, there is the potential for complacency when greater efforts are needed to reach elimination goals $[5,6]$. The "last mile" to elimination is where the participation of communities is particularly important, because as cases go down, surveillance needs to be strengthened and interventions targeted. Outbreaks during elimination setting can spark further transmission and reverse hard-achieved gains. Furthermore, as falciparum malaria declines, the burden of vivax becomes increasingly apparent [27]. Vivax is different to falciparum in terms of biology, treatment, and control, with control and elimination complicated by residual hyponozoites that can reactivate years later $[27,28]$. Sustained community engagement that addresses this complexity is essential to ensure vivax malaria is prioritized and elimination of all malaria species can be achieved.

In the context of declining malaria in the GMS, this study explored the perspectives of policy makers and researchers involved in malaria prevention and control across the region on the role of community engagement. Overall, the respondents viewed the goal of community engagement as promoting participation in malaria research or programmatic interventions. Respecting and building on existing leadership (hierarchical) structures was seen as an essential (first) step in engagement. Interactions with community members that consisted of dialogue, and being responsive to the concerns, with research messages delivered using creative forms, such as visual methods were deemed important. There was much less consensus about the issue of incentives in research and as part of community engagement and there was some confusion about the different types of payments made. Researchers however saw some sort of payment as necessary to compensate opportunity costs, particularly when participating in research. Meaningful engagement with the community members that entailed participatory methods, such as recruiting local human resources and building relationship over the length of time to build trust, was deemed critical despite various challenges.

The role of trust in community engagement has been widely discussed, although it is generally described as an intermediary step to achieve an outcome $[1,19]$. Building trust and relationship is critical for any research intervention or programs to succeed in terms of community participation and acceptance [19, $29,30]$. The interviewed policy makers and researchers however described building trust as a goal in itself. Trust can exist between individuals (interpersonal trust), or between a person and an institution (institutional trust) [31, 32]. 
Trust is often based on positive relationship with communities. To build such relationships, researchers have described the value of involving persons who are familiar and are trusted by potential participants. This may mean collaborating with an influential or popular leader. Yet this has potential pitfalls in politically divided communities $[14,21]$. Once settled in a community, program staff and researchers can build relationships and trust through their presence and interactions over time [33,34]. These relationship are however affected by the institutions to which they are connected and past experiences of the institution, and its wider reputation [32]. Researchers and program staff based in communities can struggle to balance their positions as a representative of a research institution or implementor and a member of the community [34]. Staff based in communities also experience dilemmas when seeking to abide by the research protocol but aware of the realities in communities and embedded in social relationships. For instance, providing assistance to a non-participant may fall outside the scope of a study protocol where a field staff may feel vulnerable by his/her desire to be of help [35]. Future research and program implementation should invest in preparing community-based staff for such situations. Continued support and motivations to community-based malaria workers are essential in sustaining the malaria elimination efforts [36].

One of the first steps in initiating community engagement for research and programmatic intervention is engaging with authorities at various levels all the way down to community's leadership structure [21, 37]. Because of the shift in approach from conventional vertical programs to horizontal and community directed approach, authority engagement seems to be discounted in an attempt to be seen as favoring community directed approach $[4,9,38]$. This may have resulted authority engagement to be inconsistently articulated in the community engagement scholarship. Respecting and engaging with the authorities is critical in capitalizing the existing social network and influence borne by the structure. Embedded within the authority and leadership structure is legitimacy and institutional trust that take many years to develop [32]. Most research and programmatic interventions in certain ways engage with the authorities and thus draws on authority's legitimacy, trust and legacy [32]. Nonetheless, sometimes relying on formal authorities alone can have adverse consequences, particular in politically divided communities such as in Thai-Myanmar border $[10,11,39]$.

Engaging authority figures was invariably reported to be a critical (step) but both policymakers and researchers emphasized that authority engagement cannot be a replacement to engagement with community members. Perspectives about community engagement boiled down to the quality of engagement with community members such as building relationship with the community members, collaborating in some forms with the community members $[8,14,15,19,39]$. Researchers and policymakers both tended to imply engaging community members as genuinely as possible to be the major strategy. Details of how that could be achieved was not often articulated but challenges to such an engagement was frequently reported that included constraints related to budget for the engagement, length of duration at the community, and barriers inherent in characteristics of the community such as war, conflict, linguistic and ethnic diversity, political division/partisanship, poor roadways, and importantly the human factors, that is human resources to reach out in extreme conditions $[5,23]$. 
Researchers and policymakers emphasized the role of community engagement in effective communication with community members. In the GMS, malaria transmission is now generally found in isolated communities along international borders where literacy levels are often particularly low. This presents particular challenges for researchers and program staff who must ensure that community members understand the research/intervention [40]. Facilitating the comprehensibility of research message in creative ways, such as utilizing participatory drama [41], art and theatre [42], pictorial/visual description of the study [21], and audio-visual methods can assist communicate information about the study or intervention and improve participation.

Reimbursement, compensation, and incentives have different meanings, implications and impact in research and programs [43]. Reimbursement (in cash or other forms) is intended to cover costs incurred during participation in the research or program, compensation refers to compensating for opportunity costs, and incentives can be both material and non-material rewards for participation [43]. Policymakers echoed concerns about payments in general, particularly that they could be unsustainable and potentially trigger 'undue inducement' to participate in research/programs [44]. Researchers saw reimbursement and compensation as an essential feature of participation, and it was deemed 'unethical' not to provide reimbursement and compensation.

Differences in opinion related to providing payments to potential participants between policymakers and researchers were likely rooted to their experience and the practices of research and programs: community members are far less likely to receive any payments for participating in a programmatic intervention compared to research. Researchers saw providing health services where needed (ancillary care) and community benefits rather than individual benefits as more appropriate in many remote and underprivileged region where malaria research is undertaken $[8,11]$. In the broader global health scholarships, offering benefits, such as health services or other sorts of payments, to participants in lessprivileged communities reflects existing power and wealth inequalities [44-50]. In that sense, researchers and research institutions could offer sustainable solutions to these embedded structural differences, that for example can include promoting local employment, skills and capacity development, and contribution in promoting health services.

Human resources are pivotal to community engagement because researchers who interact with the community are seen to be the representative of the research or programs [21]. Community members place their trust in the staff who they interact with based on who they are (competence), institutional affiliation (institutional trust) and their local cultural knowledge [32]. Research representatives, preferably community members with shared cultural knowledge are preferred over outsiders to facilitate communication [51]. Also, a community member will be always accessible regardless of the scope and duration of the research project. This also means that the community member who is a resident can maintain 'a presence' in the community which can strengthen accountability, responsiveness and a sense of support to the community members. 
Despite these advantages, community members also evaluate the representative in terms of who the person is, his/her demeanor, political affiliation, interests, reputation and competence. Thus, it is essential that local human resources are congenial to all community members. Employing community members who are selected by the research team also means that they are seen to be part of the research team rather than a community member [33]. Tensions and jealousies could also arise because of the selection process $[52,53]$. A transparent recruitment process led by the community can help to overcome some of these challenges.

\section{Strengths and limitations}

Respondents include a diverse group of policy makers and researchers based in ministries of health across the GMS and in research institutions located in several GMS states. Interviews were conducted both online and in-person. Many of the respondents had full agendas and the flexibility of online interviewing meant that a larger and more diverse group could be recruited. Conducting the interviews in English was one potential limitation although all but one of the respondents was comfortable with this and both policy makers and researchers were accustomed to participating in international events for which the lingua franca was English. One interview responded to written interview questions by email. Although the responses were likely influenced by the different format, this enabled the inclusion of the perspective of a policy maker who was less comfortable expressing oneself in English.

\section{Conclusion}

In the context of declining malaria transmission and aims to reach elimination in GMS states, researchers and policymakers in the region emphasized the importance of community engagement in promoting participation in research and intervention programs. They saw building trust with the community as an important way to achieve this. Involving community authority/leadership structures was seen as key to engagement activities, although they recognized that this required attention to existing political affiliation and other social relationship. They identified constraints, such as geographic remoteness, and social, cultural, and linguistic diversity as barriers to meaningful engagement. Local staff were viewed as a critical component of community engagement who could connect researchers or policy makers and prospective participants. Sharing information with community members, using various tools, for example, creative and participatory messages, was highlighted. Given the difficulties of the "last mile" to elimination, sustained investment in community engagement is needed in isolated areas of the GMS where malaria transmission continues.

\section{Abbreviations}

CE: Community Engagement; GMS: Greater Mekong subregion; MDA: Mass Drug Administration; ME: Mass Elimination; TME: Targeted Malaria Elimination; WHO: World Health Organization 


\section{Declarations}

\section{Acknowledgements}

We thank the study participants and communities, village malaria workers and local authorities. We also thank the TME community engagement team.

\section{Authors' contributions}

NK, BA, and CP designed the study and feedback was provided by all other authors. NK conducted interviews. NK and BA analyzed the data. LvS provided stimulating discussions around the central role of trust in CE. BA and NK wrote the first draft of the manuscript and was revised by all the authors.

\section{Funding}

Mahidol Oxford Tropical Medicine Research Unit is funded by the Wellcome Trust of Great Britain (Reference 101148/Z/13/Z). This study was funded by the Bill and Melinda Gates Foundation BMGF OPP1081420 and a Wellcome Trust Strategic Award (096527)

\section{Availability of data and materials}

The data is available upon request to the Mahidol Oxford Tropical Medicine Research Unit Data Access Committee (http://www.tropmedres.ac/data-sharing) complying with the data access policy (http://www.tropmedres.ac/_asset/file/data-sharing-policy-v1-0.pdf).

\section{Ethics approval and consent to participate}

Approval was obtained from the National Ethics Committee for Health Research Cambodia (NECHR 0042 \& 0051), the Oxford Tropical Research Ethics Committee (OXTREC; 1017-13). This study is part of the clinical trial registered at clinicaltrials.gov (NCT01872702). Verbal informed consent was obtained from all the respondents.

\section{Consent for publication}

Not applicable.

\section{Competing interests}


The authors declare that they have no competing interests.

\section{References}

1. Adhikari B, Vincent R, Wong G, Duddy C, Richardson E, Lavery JV, Molyneux S: A realist review of community engagement with health research. Wellcome Open Res 2019, 4:87.

2. Adhikari B, Pell C, Cheah PY: Community engagement and ethical global health research. Glob Bioeth 2020, 31:1-12.

3. CDC: Principles of Community Engagement. NIH Publication No 11-7782 2011, 2nd edition.

4. Adhikari B, James N, Newby G, von Seidlein L, White NJ, Day NP, Dondorp AM, Pell C, Cheah PY: Community engagement and population coverage in mass anti-malarial administrations: a systematic literature review. Malar J 2016, 15:523.

5. Kaehler N, Adhikari B, Cheah PY, von Seidlein L, Day NPJ, Paris DH, Tanner M, Pell C: Prospects and strategies for malaria elimination in the Greater Mekong Sub-region: a qualitative study. Malar $J$ 2019, 18:203.

6. Whittaker $\mathrm{M}$, Smith $\mathrm{C}$ : Reimagining malaria: five reasons to strengthen community engagement in the lead up to malaria elimination. Malar J 2015, 14:410.

7. Baltzell K, Harvard K, Hanley M, Gosling R, Chen I: What is community engagement and how can it drive malaria elimination? Case studies and stakeholder interviews. Malar J 2019, 18:245.

8. Pell CL, Adhikari B, Myo Thwin M, Kajeechiwa L, Nosten S, Nosten FH, Sahan KM, Smithuis FM, Nguyen TN, Hien TT, et al: Community engagement, social context and coverage of mass antimalarial administration: Comparative findings from multi-site research in the Greater Mekong subRegion. PLoS One 2019, 14:e0214280.

9. Atkinson JA, Vallely A, Fitzgerald L, Whittaker M, Tanner M: The architecture and effect of participation: a systematic review of community participation for communicable disease control and elimination. Implications for malaria elimination. Malar J 2011, 10:225.

10. Kajeechiwa L, Thwin MM, Nosten S, Tun SW, Parker D, von Seidlein L, Tangseefa D, Nosten F, Cheah PY: Community engagement for the rapid elimination of malaria: the case of Kayin State, Myanmar. Wellcome Open Res 2017, 2:59.

11. Kajeechiwa L, Thwin MM, Shee PW, Yee NL, Elvina E, Peapah P, Kyawt K, Oo PT, PoWah W, Min JR, et al: The acceptability of mass administrations of anti-malarial drugs as part of targeted malaria elimination in villages along the Thai-Myanmar border. Malar J 2016, 15:494.

12. Nguyen TN, Thu PN, Hung NT, Son DH, Tien NT, Van Dung N, Quang HH, Seidlein LV, Cheah PY, Dondorp AM, et al: Community perceptions of targeted anti-malarial mass drug administrations in two provinces in Vietnam: a quantitative survey. Malar J 2017, 16:17.

13. Pell C, Tripura R, Nguon C, Cheah P, Davoeung C, Heng C, Dara L, Sareth M, Dondorp A, von Seidlein L, Peto TJ: Mass anti-malarial administration in western Cambodia: a qualitative study of factors affecting coverage. Malar J 2017, 16:206. 
14. Peto TJ, Tripura R, Davoeung C, Nguon C, Nou S, Heng C, Kunthea P, Adhikari B, Lim R, James N, et al: Reflections on a Community Engagement Strategy for Mass Antimalarial Drug Administration in Cambodia. Am J Trop Med Hyg 2018, 98:100-104.

15. Sahan K, Pell C, Smithuis F, Phyo AK, Maung SM, Indrasuta C, Dondorp AM, White NJ, Day NP, von Seidlein L, Cheah PY: Community engagement and the social context of targeted malaria treatment: a qualitative study in Kayin (Karen) State, Myanmar. Malar J 2017, 16:75.

16. Kaneko A: A community-directed strategy for sustainable malaria elimination on islands: short-term MDA integrated with ITNs and robust surveillance. Acta Trop 2010, 114:177-183.

17. CDIS Group: Community-directed interventions for priority health problems in Africa: results of a multicountry study. Bull World Health Organ 2010, 88:509-518.

18. Reed MS, Vella S, Challies E, De Vente J, Frewer L, Hohenwallner-Ries D, Huber T, Neumann RK, Oughton EA, Sidoli del Ceno J: A theory of participation: what makes stakeholder and public engagement in environmental management work? Restoration ecology 2018, 26:S7-S17.

19. Adhikari B, Phommasone K, Kommarasy P, Soundala X, Souvanthong P, Pongvongsa T, Henriques G, Newton PN, White NJ, Day NPJ, et al: Why do people participate in mass anti-malarial administration? Findings from a qualitative study in Nong District, Savannakhet Province, Lao PDR (Laos). Malar J 2018, 17:15.

20. Adhikari B, Phommasone K, Pongvongsa T, Kommarasy P, Soundala X, Henriques G, White NJ, Day NPJ, Dondorp AM, von Seidlein L, et al: Factors associated with population coverage of targeted malaria elimination (TME) in southern Savannakhet Province, Lao PDR. Malar J 2017, 16:424.

21. Adhikari B, Pell C, Phommasone K, Soundala X, Kommarasy P, Pongvongsa T, Henriques G, Day NPJ, Mayxay M, Cheah PY: Elements of effective community engagement: lessons from a targeted malaria elimination study in Lao PDR (Laos). Glob Health Action 2017, 10:1366136.

22. King KF, Kolopack P, Merritt MW, Lavery JV: Community engagement and the human infrastructure of global health research. BMC Med Ethics 2014, 15:84.

23. Kaehler N, Adhikari B, Cheah PY, Day NPJ, Paris DH, Tanner M, Pell C: The promise, problems and pitfalls of mass drug administration for malaria elimination: a qualitative study with scientists and policymakers. Int Health 2019, 11:166-176.

24. Glasser B, Strauss A: The Discovery of Grounded Theory: Strategies for Qualitative Research. New York: Aldine Publishing Company; 1967.

25. Mack N: Qualitative research methods: A data collector's field guide. 2005.

26. von Seidlein L, Peto TJ, Landier J, Nguyen TN, Tripura R, Phommasone K, Pongvongsa T, Lwin KM, Keereecharoen L, Kajeechiwa L, et al: The impact of targeted malaria elimination with mass drug administrations on falciparum malaria in Southeast Asia: A cluster randomised trial. PLoS Med 2019, 16:e1002745.

27. Adhikari B, Awab GR, von Seidlein L: Rolling out the radical cure for vivax malaria in Asia: a qualitative study among policy makers and stakeholders. Malar J 2021, 20:164. 
28. Rijal KR, Adhikari B, Ghimire P, Banjara MR, Das Thakur G, Hanboonkunupakarn B, Imwong M, Chotivanich K, Day NPJ, White NJ, Pukrittayakamee S: Efficacy of Primaquine in Preventing Shortand Long-Latency Plasmodium vivax Relapses in Nepal. J Infect Dis 2019, 220:448-456.

29. Geissler PW, Kelly A, Imoukhuede B, Pool R: 'He is now like a brother, I can even give him some blood'-relational ethics and material exchanges in a malaria vaccine 'trial community' in The Gambia. Soc Sci Med 2008, 67:696-707.

30. Adhikari B, Cheah PY: Vaccine hesitancy in the COVID-19 era. Lancet Infect Dis 2021, 21:1086.

31. Gilson L: Trust and the development of health care as a social institution. Soc Sci Med 2003, 56:1453-1468.

32. Molyneux CS, Peshu N, Marsh K: Trust and informed consent: insights from community members on the Kenyan coast. Soc Sci Med 2005, 61:1463-1473.

33. Mlotshwa L, Harris B, Schneider H, Moshabela M: Exploring the perceptions and experiences of community health workers using role identity theory. Glob Health Action 2015, 8:28045.

34. Kamuya DM, Theobald SJ, Munywoki PK, Koech D, Geissler WP, Molyneux SC: Evolving friendships and shifting ethical dilemmas: fieldworkers' experiences in a short term community based study in Kenya. Dev World Bioeth 2013, 13:1-9.

35. Molyneux S, Kamuya D, Marsh V: Community members employed on research projects face crucial, often under-recognized, ethical dilemmas. Am J Bioeth 2010, 10:24-26.

36. Canavati SE, Lawpoolsri S, Quintero CE, Nguon C, Ly P, Pukrittayakamee S, Sintasath D, Singhasivanon P, Peeters Grietens K, Whittaker MA: Village malaria worker performance key to the elimination of artemisinin-resistant malaria: a Western Cambodia health system assessment. Malar J 2016, 15:282.

37. Kuehne A, Tiffany A, Lasry E, Janssens M, Besse C, Okonta C, Larbi K, Pah AC, Danis K, Porten K: Impact and Lessons Learned from Mass Drug Administrations of Malaria Chemoprevention during the Ebola Outbreak in Monrovia, Liberia, 2014. PLoS One 2016, 11:e0161311.

38. Lavery JV, Tinadana PO, Scott TW, Harrington LC, Ramsey JM, Ytuarte-Nunez C, James AA: Towards a framework for community engagement in global health research. Trends Parasito/ 2010, 26:279283.

39. Tangseefa D, Monthathip K, Tuenpakdee N, Konig A, Kajeechiwa L, Thwin MM, Nosten S, Tun SW, Ma K, Hashmi A, et al: "Nine Dimensions": A multidisciplinary approach for community engagement in a complex postwar border region as part of the targeted malaria elimination in Karen/Kayin State, Myanmar. Wellcome Open Res 2018, 3:116.

40. Participants in the Community E, Consent Workshop KKM: Consent and community engagement in diverse research contexts. J Empir Res Hum Res Ethics 2013, 8:1-18.

41. Lim R, Peto TJ, Tripura R, Cheah PY: Village Drama Against Malaria. Lancet 2016, 388:2990.

42. Nguon C, Dysoley L, Davoeung C, Sovann Y, Sanann N, Sareth M, Kunthea P, Vuth S, Sovann K, Kol K, et al: Art and theatre for health in rural Cambodia. Glob Bioeth 2018, 29:16-21. 
43. Gelinas L, Largent EA, Cohen IG, Kornetsky S, Bierer BE, Fernandez Lynch H: A Framework for Ethical Payment to Research Participants. N Engl J Med 2018, 378:766-771.

44. Emanuel EJ, Currie XE, Herman A, Project P: Undue inducement in clinical research in developing countries: is it a worry? Lancet 2005, 366:336-340.

45. Belsky L, Richardson HS: Medical researchers' ancillary clinical care responsibilities. BMJ 2004, 328:1494-1496.

46. Dickert N, DeRiemer K, Duffy PE, Garcia-Garcia L, Mutabingwa TK, Sina BJ, Tindana P, Lie R: Ancillary-care responsibilities in observational research: two cases, two issues. Lancet 2007, 369:874-877.

47. Dickert N, Wendler D: Ancillary care obligations of medical researchers. JAMA 2009, 302:424-428.

48. Haire BG, Ogundokun 0 : Ethics of ancillary care in clinical trials in low income countries: a Nigerian case study. Afr J Reprod Health 2014, 18:135-142.

49. Henderson GE, Churchill LR, Davis AM, Easter MM, Grady C, Joffe S, Kass N, King NM, Lidz CW, Miller FG, et al: Clinical trials and medical care: defining the therapeutic misconception. PLoS Med 2007, 4:e324.

50. Participants in Georgetown University Workshop on Ancillary-Care Obligations of Medical Researchers Working in Developing C: The ancillary-care obligations of medical researchers working in developing countries. PLoS Med 2008, 5:e90.

51. Kolopack PA, Parsons JA, Lavery JV: What makes community engagement effective?: Lessons from the Eliminate Dengue Program in Queensland Australia. PLoS Neg/ Trop Dis 2015, 9:e0003713.

52. Gikonyo C, Bejon P, Marsh V, Molyneux S: Taking social relationships seriously: lessons learned from the informed consent practices of a vaccine trial on the Kenyan Coast. Soc Sci Med 2008, 67:708720 .

53. Gooding K, Phiri M, Peterson I, Parker M, Desmond N: Six dimensions of research trial acceptability: how much, what, when, in what circumstances, to whom and why? Soc Sci Med 2018, 213:190-198.

\section{Figures}




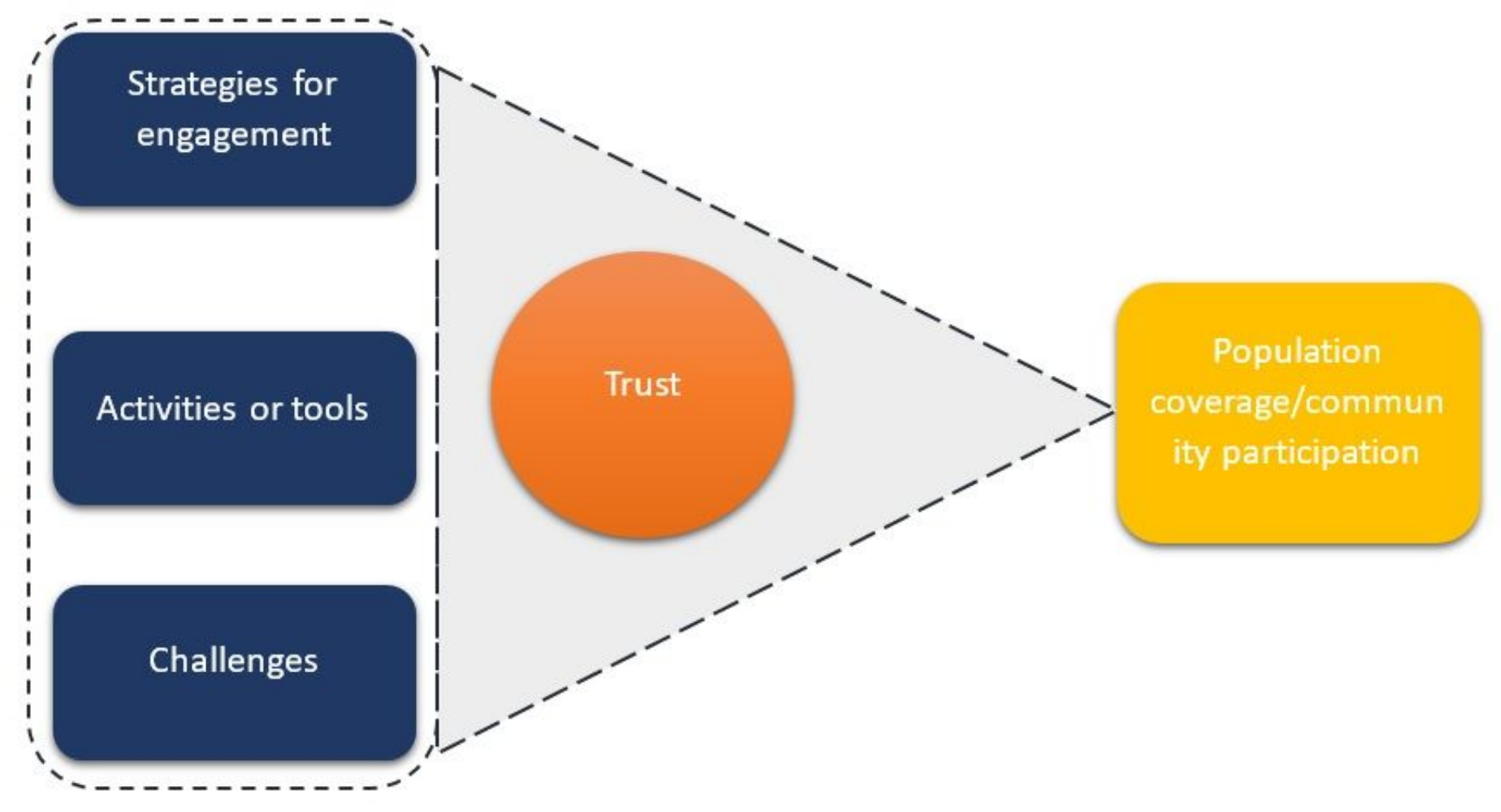

Figure 1

Aims of community engagement relevant for malaria elimination. 